\title{
Prevalence and associated factors of suicidality in Japanese adolescents: results from a population-based questionnaire survey
}

Shinichiro Nagamitsu ${ }^{1 *}$ D, Masakazu Mimaki ${ }^{2}$, Kenshi Koyanagi ${ }^{3}$, Natsuko Tokita ${ }^{4}$, Yoriko Kobayashi ${ }^{5}$, Ritsuko Hattori ${ }^{6}$, Ryuta Ishii ${ }^{1}$, Michiko Matsuoka ${ }^{7}$, Yushiro Yamashita ${ }^{1}$, Zentaro Yamagata ${ }^{8}$, Takashi Igarashi ${ }^{9}$ and Paul E. Croarkin ${ }^{10}$

\begin{abstract}
Background: Suicide is the leading cause of death among Japanese adolescents. However, knowledge gaps regarding contemporary demographics and factors associated with suicidality among Japanese adolescents are a major concern. This study examined the prevalence of suicidality among Japanese adolescents and investigated associated factors.

Methods: A population-based questionnaire survey investigating general health was administered to 22,419 adolescents aged 13-18 years. The 29-item questionnaire covered emotional status, family function, cyberbullying, suicidality, and stressors (e.g., relationships with parents/friends, school performance, and sexual identity). We conducted multiple logistic regression analysis to identify factors associated with suicidality in this population.

Results: The prevalence of suicidal ideation was $21.6 \%$ in males and $28.5 \%$ in females, and that of attempted suicide was $3.5 \%$ in males and $6.6 \%$ and in females. Bullying and stress related to family relationships had the strongest associations with suicidality. Exposure to cyberbullying had the highest odds ratio for both junior high (3.1, 95\% confidence interval [Cl] 2.1-4.4) and high school students (3.6, 95\% Cl 2.5-5.3). Other factors significantly associated with suicidality were sex, emotional status, and stress about relationships with friends, sexual identity, school records, and academic course. Adolescents accessed a variety of resources to cope with stressors, with the Internet being the most common resource consulted.
\end{abstract}

Conclusions: Suicidality is commonly experienced among Japanese adolescents. Although there are many associated risk factors, cyberbullying is of particular concern. Recognition of factors associated with adolescent suicidality will inform further research and suicide prevention efforts for healthcare providers and families.

Keywords: Suicide attempts, Adolescent, Child, Suicidal ideation, Cyberbullying

\footnotetext{
* Correspondence: kaoru@med.kurume-u.ac.jp

'Department of Pediatrics and Child Health, Kurume University School of Medicine, 67 Asahi-machi Kurume, Fukuoka 830-0011, Japan

Full list of author information is available at the end of the article
}

(C) The Author(s). 2020 Open Access This article is licensed under a Creative Commons Attribution 4.0 International License, which permits use, sharing, adaptation, distribution and reproduction in any medium or format, as long as you give appropriate credit to the original author(s) and the source, provide a link to the Creative Commons licence, and indicate if changes were made. The images or other third party material in this article are included in the article's Creative Commons licence, unless indicated otherwise in a credit line to the material. If material is not included in the article's Creative Commons licence and your intended use is not permitted by statutory regulation or exceeds the permitted use, you will need to obtain permission directly from the copyright holder. To view a copy of this licence, visit http://creativecommons.org/licenses/by/4.0/ The Creative Commons Public Domain Dedication waiver (http://creativecommons.org/publicdomain/zero/1.0/) applies to the data made available in this article, unless otherwise stated in a credit line to the data. 


\section{Background}

The Promotion Council for Healthy Parents and Children 21 database (operated by Japan's Ministry of Health, Labour and Welfare) recently identified a number of positive trends in adolescent behaviors and health [1]. For example, rates of smoking, alcohol consumption, sexually transmitted infections, induced abortions, and obesity have decreased in recent decades. However, the suicide rates among young people aged $10-14$ and $15-19$ years rose between 2002 ( 0.8 and 7.5 per 100,000 , respectively) and 2012 (1.3 and 8.5 per 100,000, respectively) [2]. The prevalence of suicidal ideation and suicidal attempts has been reported in various countries, although the reported ranges differ. In some Western countries, the reported prevalence of suicidal ideation was $12.1-22.0 \%$ and that of suicidal attempts was 1.0-7.6\% [3-7]. However, low- and middle-income countries showed higher prevalence rates [8-10], and some Asian countries had equal or lower prevalence rates than those reported for Western countries [11-13].

Prior research examined factors associated with suicidal ideation or attempts among adolescents [6, 7, 13-21]. The majority of youth with suicidality have preexisting psychiatric disorders. Saffer et al. [17] reported that lower parental bonding may be an important risk factor for youth suicidal behavior. Other studies suggested that adolescents who were either victims or perpetrators of bullying had an increased risk for suicide [14, 16]. Academic stressors and conflicted feelings about sexual identity are other putative risk factors for suicide among adolescents [18]. Recently, several cross-sectional studies showed associations between personal/social risk factors and suicidality among Japanese adolescents. Hikikomori (prolonged, severe social withdrawal and isolation), preference for solitude, low body mass index, appetite loss, violence, and psychoticlike experiences have been proposed as significant risk factors for Japanese adolescents [20-26]. Some metaanalyses have identified risk factors that were significantly associated with higher odds of suicidal ideation and attempts in adolescents, including stressful life events, bullying victimization, and peer victimization [14, 27-29]. Suicide is the leading cause of death among Japanese adolescents, and effective strategies are required to prevent suicide in this population. The Japanese government officially announced that poor school academic records and stress about academic courses were the most significant causes of suicide among school students [30]. However, multiple logistic regression analysis is necessary to identify individual and environmental factors associated with suicidality among adolescents.

The present study aimed to examine the prevalence of suicidal ideation and attempts among Japanese junior high-school and high school students. We also examined correlations between suicidal ideation or attempts and potential associated factors, including sex, age, grade, family structure, family function, emotional status, cyberbullying, number of friends, stressors (e.g., relationships with friends, relationships with parents, school records, academic course, sexual identity), and geographic region. Broadly, the findings may inform public health initiatives focused on adolescent health. We hypothesized that the prevalence of suicidality in our study would be similar to that found internationally, and bullying would be associated with suicide attempts.

\section{Methods \\ Participants}

Data for this study were drawn from a Promotion Council for Healthy Parents and Children survey conducted in November-December, 2016. Six education committees approved representative schools to participate in that survey. In total, we analyzed data for 22,419 students from 36 public junior high schools, five private junior high schools, 10 public high schools, and six private high schools. Participating junior high school students were aged 13-15 years (grades 7-9) and high school students were aged 16-18 years (grades 10-12). The participating schools were located in four urban cities (population over 1 million), four suburban cities (population around 300,000), and two rural areas (population around 50,000). These areas covered much of Japan, including Tokyo, Kyoto, Fukuoka, Tochigi, Aichi, and Nagasaki prefectures.

\section{Questionnaire content and survey procedure}

The Promotion Council for Healthy Parents and Children 21 (Second Phase) reviewed and approved the questionnaire and survey process. The 29-item questionnaire covered: general information (age, sex, school grade, number of siblings, sleep habits, and Internet use); general feelings (emotional status and suicidality); family function; bullying (school or cyber); general stressors (e.g., relationships with family/friends, sexual identity, pregnancy, school bullying, and substance use) and stress about future events (e.g., marriage and raising children). We also examined resources that participants consulted to cope with stressors. They were asked to select the most useful single resource for each stressor from four options (parents, friends, school teacher/s, and the Internet). Table 1 presents examples of survey questions. Participants' parents were informed about this questionnaire survey by letter, and the participating schools obtained passive informed consent from participants. The questionnaire was distributed directly to participating adolescents. Their class teachers explained the purpose of the study, and the anonymous selfadministered questionnaire was completed during class time. Participants placed their completed questionnaire 
Table 1 Questionnaire items (sample)

Q1 What is your school grade?
Q3 What is your sex?
Q4 How many siblings do you have?
Q8 How many friends do you have? (very many, many, not so many,
very few, unknown)
Q10 How often do you feel happy? (always, often, sometimes, rarely,
never)
Q11 How often do you feel well? (always, often, sometimes, rarely,
never)
Q12 How often do you feel lonely? (always, often, sometimes, rarely,
never)
Q13 How often do you talk with your family? (always, often, sometimes,
rarely, never)
Q14 Have you ever experienced cyberbullying? (yes, no)
Q15 In the past year, have you seriously considered killing yourself? (no,
sometimes, always, attempted suicide, no idea)
Q17 Do you have stressors about the following: body image; secondary
sexual characteristics; friends; conventional bullying; parents; siblings;
school records; opposite sex; sexual identity or intercourse; sexually
transmitted infections; induced abortion; contraception; marriage;
pregnancy, child care; physical illness; academic course; alcohol,
smoking, or substance use?

into a sealed envelope. Their teachers then collected the envelopes and sent them to Kurume University.

\section{Statistical procedure and analysis}

The survey data were used to determine the prevalence of suicidal ideation, suicide attempts, and potential associated factors among Japanese adolescents. To examine ideas about suicidality, participants were asked, "In the past year, have you seriously considered killing yourself?" (Q15). Participants were requested to select one of five response choices (never, sometimes, always, have attempted suicide, and no idea). We defined participants who selected "never" as having no suicidality, those that selected either "sometimes" or "always" as having suicidal ideation, and those who selected "have attempted suicide" as suicide attempts. To minimize the invasive effects of the survey on participants, responses for suicidal ideation and suicidal behaviors (suicide attempts) were listed in one answer column. We examined factors potentially associated with suicidality: grade (Q1); sex (Q3); number of siblings $(\mathrm{Q} 4)$; number of friends $(\mathrm{Q} 8)$; happiness (Q10); wellness (Q11); loneliness (Q12); amount of family conversation (Q13); experience of cyberbullying (Q14); and stressors (Q17). In Q17, participants were asked whether they had experienced specific stressors: relationships with friends; school bullying; relationships with parents; school records; relationships with the opposite sex; sexual identity; academic course; and tobacco or substance use. Each item in Q17 was listed as a noun in the questionnaire, and participants answered either "yes" or "no." Geographic region was also examined as a factor potentially associated with suicidality.

We first determined the prevalence of suicidality by grade and sex. Then, we counted the numbers of stressors and calculated the ratio of consultation resources for each stressor. Univariate logistic regression analysis was used to examine factors potentially associated with suicidality among adolescents, with respect to both ideation and attempts. Separate analyses were conducted for junior and high school participants because we speculated that factors associated with suicidality could differ between junior high school and high school students. We conducted multiple logistic regression analysis to estimate odds ratios (OR). Potential confounders (e.g., grade, sex, number of siblings, number of friends, and stressors, as listed in Table 1) were included in the model as covariates.

\section{Results \\ Participants}

In total, there were 22,419 respondents (48\% female) aged 13-18 years. There were 13,285 junior high and 9134 high school students. Notably, adolescents absent from school at the time of the survey were unable to participate. Participant numbers in each grade were: 4371 (7th grade); 4486 (8th grade); 4396 (9th grade); 3683 (10th grade); 3024 (11th grade); 2396 (12th grade); and 63 (grade undetermined). The distribution of participants' locations and school types is presented in Table 2 . There were no participants from private schools in rural areas.

\section{Number of participants experiencing cyberbullying and stressors}

There were $402(1.8 \%)$ participants with experience of cyberbullying. The numbers of participants that reported each stressor type were: relationships with friends, 5381 (24.0\%); school bullying, 573 (2.6\%); relationships with parents, 2062 (9.2\%); school records, 13,391 (59.7\%); relationships with the opposite sex, 2383 (10.6\%); sexual identity or intercourse, 553 (2.5\%); academic course, 13, 477 (60.1\%); tobacco use, 363 (1.6\%); and substance use, 167 (0.7\%).

\section{Prevalence of suicide ideation and suicide attempt}

The overall prevalence of suicidal ideation was $25.7 \%$, and that of attempted suicide was $5.4 \%$. Almost twice as many female adolescents had made a suicide attempt than males (6.6\% vs. $3.5 \%)$. Notably, we observed little difference in the prevalence of suicide attempts in the 7 th grade (Table 3 ). 
Table 2 Participants' geographic location and school type

\begin{tabular}{|c|c|c|c|c|c|}
\hline \multirow[b]{2}{*}{ School type } & \multicolumn{2}{|c|}{ Junior high school $(n=13,285)$} & \multicolumn{2}{|c|}{ High school $(n=9134)$} & \multirow{2}{*}{$\begin{array}{l}\text { Total }(N=22,419) \\
\text { Total }\end{array}$} \\
\hline & Public & Private & Public & Private & \\
\hline \multicolumn{6}{|l|}{ Region } \\
\hline Urban & 746 & 1957 & 1304 & 3346 & 7353 \\
\hline Suburban & 8449 & 162 & 1923 & 803 & 11,337 \\
\hline Rural & 1971 & 162 & 1758 & 0 & 3729 \\
\hline
\end{tabular}

\section{Consultation resources for stressors}

Figure 1 shows the proportions of preferred resources participants' selected for various stressors. They used different resources according to the type of stressor. Many participants indicated they consulted the Internet as a resource-even for matters concerning parent relationships. Notably, few adolescents recorded teachers as resource for addressing stressors.

\section{Multivariate regression analysis}

Table 4 shows the results of univariate and multivariate logistic regression analysis. In the univariate logistic regression analysis, all covariates except school grade and number of siblings (junior high school students) were significantly associated with suicidality. The factors that showed high ORs were: experience of cyberbullying (junior high school students OR 6.5, 95\% confidence interval [CI] 4.7-8.8; high school students OR 5.6 95\% CI 4.07.7), stress about school bullying (junior high school students OR 5.3, 95\% CI 4.3-6.4; high school students OR 8.9 95\% CI 5.2-15.4), and stress about relationships with parents (junior high school students OR 5.0, 95\% CI 4.4-5.6; high school students OR 4.2, 95\% CI 3.6-4.9).

In the multivariate logistic regression analysis adjusted for confounding variables, most covariates were significantly associated with suicidality in junior high school students, with the exception of grade, number of siblings, stress about tobacco/substance use, and geographic region. By contrast, all factors except grade and stress about tobacco/substance use were significant among high school students. The factors that showed high adjusted ORs among junior high school students were: experience of cyberbullying (OR 3.1, 95\% CI 2.14.4); stress about relationships with parents (OR 2.1, 95\% CI 1.8-2.4); and stress about school bullying (OR 1.9, 95\% CI 1.5-2.4). Among high school students, the factors that showed high adjusted ORs were: experience of cyberbullying (OR 3.6, 95\% CI 2.5-5.3); stress about bullying (OR 2.6, 95\% CI 1.4-4.9); stress about sexual identity or intercourse (OR 2.2, 95\% CI 1.6-3.0); and stress about relationships with parents (OR 2.1, 95\% CI $1.8-2.5)$.

\section{Discussion}

The present study examined the prevalence of suicidality among Japanese adolescents and associated factors. This study was characterized by nationally representative large-scale data that covered urban, suburban, and rural areas in Japan. We analyzed associated factors related to general information about participants, their feelings, family function, bullying, and various stressors.

The overall prevalence of suicidal ideation and suicide attempts among Japanese adolescents was 25.7 and 5.4\%, respectively; these rates were similar to those observed in Western countries [3-7]. The prevalence was also consistent with previously reported figures for Japan [31-33]. School grade and geographic region did not appear to be associated with suicidality. However, a

Table 3 Prevalence of suicide ideation and suicide attempts

\begin{tabular}{|c|c|c|c|c|c|c|c|c|}
\hline \multirow{2}{*}{$\overline{\text { Total }}$} & & \multirow{2}{*}{$\frac{\mathbf{n}}{22,419}$} & \multicolumn{2}{|l|}{ None } & \multicolumn{2}{|c|}{ Suicidal ideation } & \multicolumn{2}{|c|}{ Suicide attempt } \\
\hline & & & 15,245 & $68.0 \%$ & 5765 & $25.7 \%$ & 1206 & $5.4 \%$ \\
\hline \multirow[t]{6}{*}{ Grade } & 7th & 4371 & 3011 & $68.9 \%$ & 1123 & $25.7 \%$ & 203 & $4.6 \%$ \\
\hline & 8th & 4486 & 3088 & $68.8 \%$ & 1130 & $25.2 \%$ & 233 & $5.2 \%$ \\
\hline & 9th & 4396 & 3043 & $69.2 \%$ & 1054 & $24.0 \%$ & 261 & $5.9 \%$ \\
\hline & 10th & 3683 & 2492 & $67.7 \%$ & 961 & $26.1 \%$ & 191 & $5.2 \%$ \\
\hline & 11th & 3024 & 1990 & $65.8 \%$ & 836 & $27.6 \%$ & 176 & $5.8 \%$ \\
\hline & 12th & 2396 & 1595 & $66.6 \%$ & 648 & $27.0 \%$ & 138 & $5.8 \%$ \\
\hline \multirow[t]{2}{*}{ Sex } & Male & 8907 & 6606 & $74.2 \%$ & 1925 & $21.6 \%$ & 309 & $3.5 \%$ \\
\hline & Female & 13,454 & 8613 & $64.0 \%$ & 3830 & $28.5 \%$ & 893 & $6.6 \%$ \\
\hline
\end{tabular}

The numbers and percentages of participants who selected "no idea" for suicidal question do not appear in the table. The numbers of participants with missing values for each factor likewise do not appear 


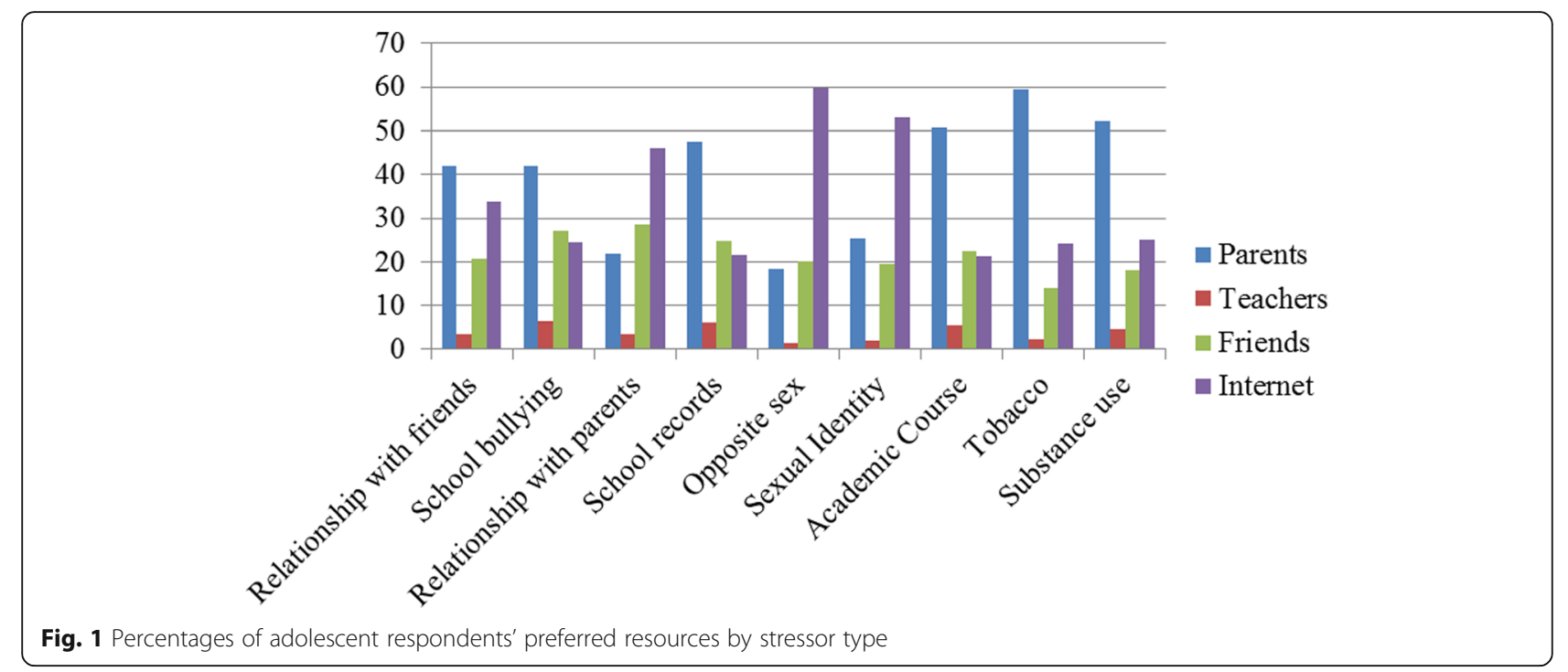

number of characteristics and perceptions appeared to be associated with suicidality in this sample. The strength of this cross-sectional survey was that we simultaneously analyzed a number of potential factors associated with adolescents' suicidality, including environmental factors and related stressors. Prior experience of cyberbullying was identified as the most significant associated factor. We also identified school bullying, and stress about relationships with parents, relationships with the opposite sex, and sexual identity or intercourse as having high ORs.

Associations between bullying (cyber or school) victimization and suicidal behavior have been reported over the past decade, and the growing number of reports is of particular concern [34-38]. Psychological distress from cyberbullying is more severe than that associated with school traditional bullying, as it is anonymous and pervasive, and can happen anytime and anywhere [37, 38]. Based on the intensity of threats and individual vulnerability of victims, cyberbullying may directly result in increased depression and suicidal behavior [35]. In the present study, the definition of cyberbullying was not determined; therefore, our findings were based on adolescents' self-reported perceptions of cyberbullying. However, $1.8 \%$ of adolescents reported having experienced cyberbullying, of which $19.9 \%$ had attempted suicide and 52.0\% had suicidal ideation (data not shown). A previous study investigated the association between level of Internet use and suicidal ideation or attempts in over 200,000 adolescents using a web-based survey; participants with a higher Internet addiction risk reported significantly higher suicidal ideation or suicide attempts [36]. Use of the Internet as a communication vehicle among children is increasing; therefore, guidance about cyberbullying should be provided in school health programs to help prevent possible suicidal behavior.
Another striking factor associated with suicidality in the present study was stress related to parental relationships. This factor showed a high OR as an associated factor among both junior high and high school students. However, the question concerning stress related to participants' relationship with their parents did not define the meaning of "relationship with parents," and it could therefore be widely interpreted. This stress might have included family support, family function, family conflict, communication, and other factors. Negative perceptions of family function or support have been reported as being significantly associated with suicidality in both community and clinical samples [6, 17, 19, 39-42]. Samm et al. [42] observed that self-reported satisfaction with family relationships and good communication with parents reduced the likelihood of suicidal thoughts in a non-clinical sample of adolescents. Susukida et al. [19] reported that individuals who perceived love from caregivers during childhood had a significantly lower prevalence of lifetime suicidal ideation than individuals without such perceptions; this finding was independent of whether the individuals lived with both biological parents during childhood. Susukida et al. [19] suggested that regardless of family structure, perceived support from caregivers during childhood is an important correlate of lifetime suicidal ideation. Similarly, in clinical samples, family discord and negative relationships with parents were associated with increased suicide risk among adolescents with depression [39-42]. Furthermore, suicidal ideation among children is associated with suicidal depression among their caregivers [31]. Evidence suggests that good relationships with parents lead to lower lifetime suicidal ideation. Therefore, it is important for health providers to assess individual family function, which may be a key factor to help prevent for suicidal ideation or attempted suicide among adolescents. 


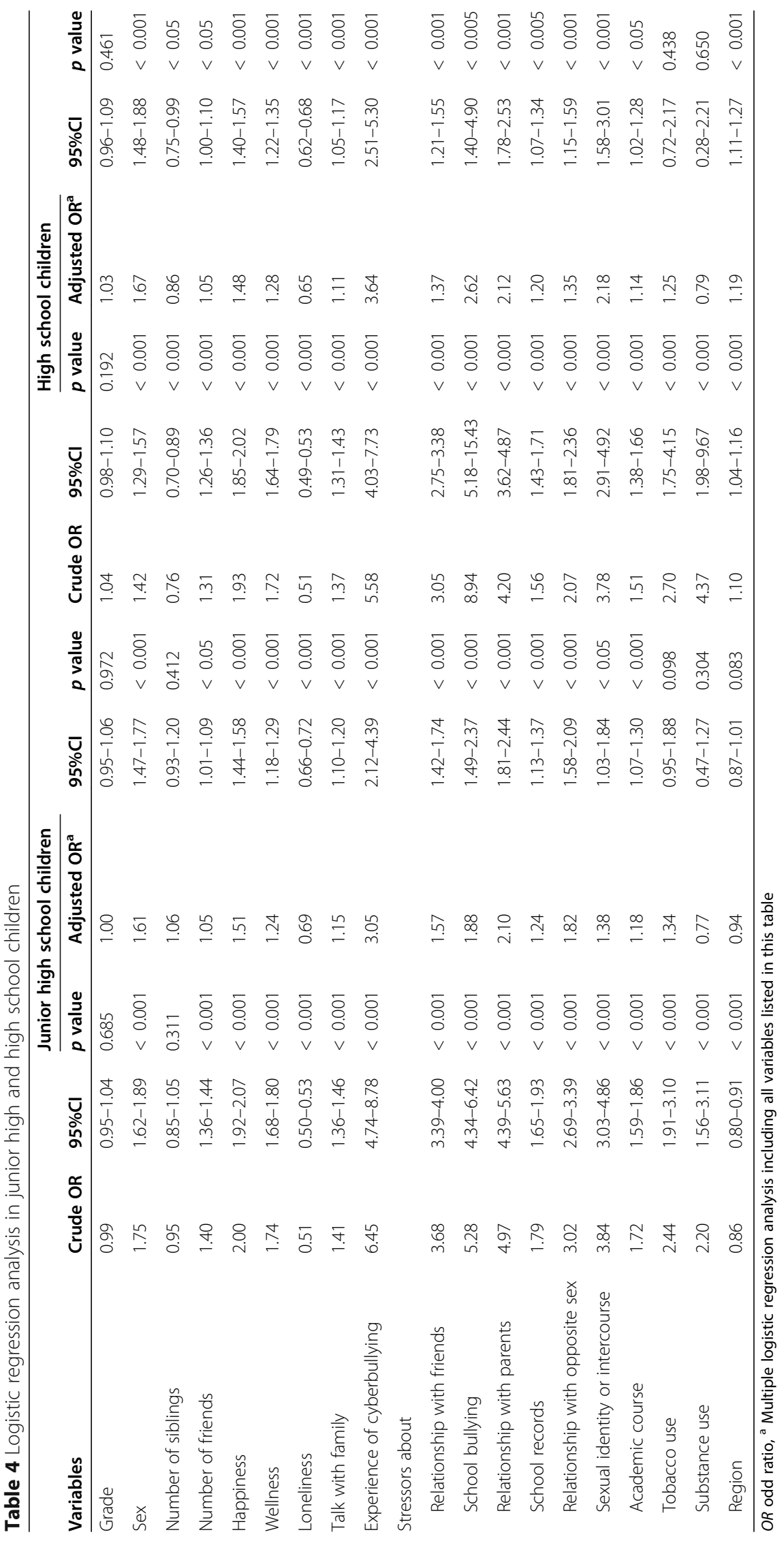


Another factor with a high OR in this study was stress related to sexual identity or intercourse-especially among high school students. Transgender adolescents have more suicide attempts than cisgender adolescents; gender identity subgroups show different rates of suicide attempts (female-to-male adolescents have the highest rate, at 50.8\%) [43]. The prevalence of transgender individuals appears to be relatively low (1.4\%) in Japan [44]; however, sexual minority adolescents remain at an increased risk for suicidality.

The number of adolescents who reported stress because of school records or their academic courses was high, and these stressors were significant risk factors for suicidality; however, the ORs were not higher than those for other factors. According to the Japanese government's official announcement, poor school academic records and stress about academic courses were the most significant causes of adolescent suicide (9.9\% of suicide cases were considered as having those conditions as a possible cause) [30]. In addition, that announcement indicated $8.8 \%$ of completed suicides were related to stressful relationships with parents, and the rate of overall bullying as a possible cause was only $1.8 \%$; however, that investigation was based on assessment by each school principle or educational committee [30]. It is imperative that school health providers consider the discrepancy between the government's official announcement and our results to develop and optimize preventive interventions.

The implication of these findings that showed many factors were associated with suicidality suggests that multiple factors simultaneously affect suicidality for adolescents rather than a single factor. Health providers and families need to keep this in mind to help prevent suicide among adolescents.

Another important finding in this study was that adolescents consulted different resources to manage stressors according to the type of stress. Our participants chose the Internet as a resource for worries or stress about the opposite sex, sexual identity, and relationships with parents. However, participants tended not to confide in their teachers, indicating reluctance to undertake help-seeking behavior. Our participants may have been concerned about confidentiality and stigma, which can prevent young people from seeking help. A growing body of evidence suggests that help-seeking behavior may influence the prevention of suicidal ideation or attempted suicide in adolescents [45-47]. Although friends, teachers, and family members are likely to be the greatest support resources for adolescents with suicidality, the majority of adolescents with suicidality do not seek help for their difficulties [48]. School-based mental health literacy educational programs are required to promote knowledge and help-seeking behavior among adolescents [49].
The present study had some limitations. The results must be considered in the context of potential response bias inherent in our survey process. First, ideally suicidal ideation and attempts would have been reviewed with two discrete questions. In our study, participants' responses for suicidal ideation and suicide attempts were listed in one answer column to minimize the invasive effects on participants. In Japan, some educational committees still have the perception that talking about suicide and suicide prevention in the classroom as an educational program may increase the possibility of suicide in a vulnerable child. For this reason, we were obliged to minimize questions pertaining directly to suicidality. However, the questionnaire for suicidality was not validated. Second, we did not perform structured diagnostic and cognitive interviews with participants, and did not ask about depressive symptoms in the questionnaire. Therefore, we did not assess depressive disorders, which may be associated with the development of suicidality. Third, we did not evaluate participants' socioeconomic status (e.g., income and education level) or family structure.

\section{Conclusion}

In conclusion, we found the prevalence of suicidal ideation and attempted suicide in Japanese adolescents was 25.7 and $5.4 \%$, respectively; these rates are similar to those observed in Western countries [3-7]. We simultaneously investigated various factors that were possibly associated with adolescents' suicidality; we identified experience of cyberbullying as the most significant associated factor. The relationship between children and their parents is also important to consider in prevention efforts regarding suicidal behavior. Further research is needed about school- and home-based mental health education by health providers and families to facilitate help-seeking behavior among adolescents.

\section{Acknowledgements \\ We would like to thank all those who helped us, especially the Board of Education, principals of the schools, and contributing students. We thank the Edanz Group (https://en-author-services.edanzgroup.com/ac) for editing a draft of this manuscript.}

\section{Authors' contributions \\ SN, MM1, YY, and TI participated in the design of this study and SN compiled the manuscript. KK, NT, YK, RH, RI, and MM2 communicated the design of the study to education committees and collected data. ZY conducted the statistical analyses. PC supervised the preparation of the manuscript. All authors read and approved the manuscript. (MM1 and MM2 correspond to Masakazu Mimaki and Michiko Matsuoka, respectively.)}

\section{Funding}

This work was supported by grants from the Ministry of Education, Culture, Sports, Science and Technology (\#19 K0266119) and the Ministry of Health, Labour and Welfare (Research Project in the fiscal year 2016 to Promote Support for Children and Child-Raising, H29Sukoyaka-005, H30ukoyaka-Ippan004, H31Sukoyaka-19DA1003), and the Japan Agency for Medical Research and Development (BIRTHDAY: 20gk0110028h0003). The funders had no role 
in the study design, collection, analysis or interpretation of the data, writing the manuscript, or the decision to submit the paper for publication.

\section{Availability of data and materials}

The datasets used in this study are available from the corresponding author on reasonable request.

\section{Ethics approval and consent to participate}

The design of this study and procedures for obtaining informed consent were approved by the Medical Ethics Committee of Kurume University School of Medicine (\#16159). Participants' parents were informed about this questionnaire survey by letter, and the participating schools obtained passive informed consent from participants. Verbal consent was obtained from the parents of participants under the age of 16 . The verbal contents were also obtained from participants, that was approved by the ethics committee. There was an opt out method for parents or students that did not want to participate in the study.

\section{Consent for publication}

Not applicable.

\section{Competing interests}

All authors declare that they have no conflicts of interest.

\section{Author details}

${ }^{1}$ Department of Pediatrics and Child Health, Kurume University School of Medicine, 67 Asahi-machi Kurume, Fukuoka 830-0011, Japan. ²Department of Pediatrics, School of Medicine Teikyo University, Tokyo, Japan. ${ }^{3}$ Nagasaki Prefectural Center of Medicine and Welfare for Children, Isahaya, Japan. ${ }^{4}$ Department of Pediatrics, School of Medicine, Keio University, Tokyo, Japan. ${ }^{5}$ Clinic of International University of Health and Welfare, Otawara, Japan. ${ }^{6}$ Faculty of Health Science Naragakuen University, Nara, Japan. ${ }^{7}$ Department of Neuropsychiatry, Kurume University School of Medicine, Kurume, Japan. ${ }^{8}$ Department of Health Sciences, School of Medicine, University of Yamanashi, Kofu, Japan. ${ }^{9}$ National Center for Child Health and Development, Tokyo, Japan. ${ }^{10}$ Department of Psychiatry and Psychology, Mayo Clinic, Rochester, USA.

\section{Received: 16 March 2020 Accepted: 28 September 2020}

\section{Published online: 06 October 2020}

\section{References}

1. Sukoyaka Oyako 21 (2018) Retrieved from http://sukoyaka21.jp/healthyparents-and-children-21. Accessed 13 Mar 2020.

2. Sukoyaka Oyako 21 (2014) Retrieved from http://rhino.med.yamanashi.ac.jp/ sukoyaka/pdf/saisyuuhyouka4.pdf. Accessed 13 Mar 2020.

3. Baiden P, Mengo C, Small E. History of Physical Teen Dating Violence and lts Association With Suicidal Behaviors Among Adolescent High School Students: Results From the 2015 Youth risk behavior survey. J Interpers Violence. 2019; 886260519860087. https://doi.org/10.1177/0886260519860087.

4. Wang J, Häusermann M, Wydler H, Mohler-Kuo M, Weiss MG. Suicidality and sexual orientation among men in Switzerland: findings from 3 probability surveys. J Psychiatr Res. 2012;46:980-6.

5. Mortier P, Auerbach RP, Alonso J, Bantjes J, Benjet C, Cuijpers P, et al. WHO WMH-ICS collaborators. Suicidal thoughts and behaviors among first-year college students: results from the WMH-ICS project. J Am Acad Child Adolesc Psychiatry. 2018;57:263-73.

6. Lipschitz JM, Yen S, Weinstock LM, Spirito A. Adolescent and caregiver perception of family functioning: relation to suicide ideation and attempts. Psychiatry Res. 2012;200:400-3.

7. Nock MK, Green JG, Hwang I, McLaughlin KA, Sampson NA, Zaslavsky AM, et al. Prevalence, correlates, and treatment of lifetime suicidal behavior among adolescents: results from the National Comorbidity Survey Replication Adolescent Supplement. JAMA Psychiatry. 2013;70:300-10.

8. Dema T, Tripathy JP, Thinley S, Rani M, Dhendup T, Laxmeshwar C, et al. Suicidal ideation and attempt among school going adolescents in Bhutan a secondary analysis of a global school-based student health survey in Bhutan 2016. BMC Public Health. 2019;19:1605.

9. Pandey AR, Bista B, Dhungana RR, Aryal KK, Chalise B, Dhimal M. Factors associated with suicidal ideation and suicidal attempts among adolescent students in Nepal: findings from global school-based students health survey. PLoS One. 2019;14:e0210383.

10. Uddin R, Burton NW, Maple M, Khan SR, Khan A. Suicidal ideation, suicide planning, and suicide attempts among adolescents in 59 low-income and middle-income countries: a population-based study. Lancet Child Adolesc Health. 2019:3:223-33.

11. Wan Y, Chen R, Ma S, McFeeters D, Sun Y, Hao J, Tao F. Associations of adverse childhood experiences and social support with self-injurious behaviour and suicidality in adolescents. Br J Psychiatry. 2019;214:146-52.

12. Law BM, Shek DT. Self-harm and suicide attempts among young Chinese adolescents in Hong Kong: prevalence, correlates, and changes. J Pediatr Adolesc Gynecol. 2013;26:S26-32.

13. Huang YH, Liu HC, Sun FJ, Tsai FJ, Huang KY, Chen TC, et al. Relationship between predictors of incident deliberate self-harm and suicide attempts among adolescents. J Adolesc Health. 2017:60:612-8.

14. Holt MK, Vivolo-Kantor AM, Polanin JR, Holland KM, DeGue S, Matjasko JL, et al. Bullying and suicidal ideation and behaviors: a meta-analysis. Pediatrics. 2015;135:e496-509.

15. Donath C, Bergmann MC, Kliem S, Hillemacher T, Baier D. Epidemiology of suicidal ideation, suicide attempts, and direct self-injurious behavior in adolescents with a migration background: a representative study. BMC Pediatr. 2019;19:45.

16. King CA, Horwitz A, Berona J, Jiang Q. Acutely suicidal adolescents who engage in bullying behavior: 1-year trajectories. J Adolesc Health. 2013;53:\$43-50.

17. Saffer BY, Glenn CR, David KE. Clarifying the relationship of parental bonding to suicide ideation and attempts. Suicide Life Threat Behav. 2015; 45:518-28.

18. Sörberg WA, Zeebari Z, Lager A, Gunnell D, Allebeck P, Falkstedt D. Suicide attempt predicted by academic performance and childhood IQ: a cohort study of 26000 children. Acta Psychiatr Scand. 2018;137:277-86.

19. Susukida R, Wilcox HC, Mendelson T. The association of lifetime suicidal ideation with perceived parental love and family structure in childhood in a nationally representative adult sample. Psychiatry Res. 2016;237:246-51.

20. Endo K, Ando S, Shimodera S, Yamasaki S, Usami S, Okazaki Y, et al. Preference for solitude, social isolation, suicidal ideation, and self-harm in adolescents. J Adolesc Health. 2017:61:187-91.

21. Fujikawa S, Ando S, Shimodera S, Koike S, Usami S, Toriyama R, et al. The Association of Current Violence from adult family members with adolescent bullying involvement and suicidal feelings. PLOS One. 2016;11:e0163707.

22. Kinoshita K, Kinoshita Y, Shimodera S, Nishida A, Inoue K, Watanabe N, et al. Not only body weight perception but also body mass index is relevant to suicidal ideation and self-harming behavior in Japanese adolescents. J Nerv Ment Dis. 2013:200:305-9.

23. Kitagawa Y, Ando S, Yamasaki S, Foo JC, Okazaki Y, Shimodera S, et al. Appetite loss as a potential predictor of suicidal ideation and self-harm in adolescents: a school-based study. Appetite. 2017;111:7-11.

24. Nishida A, Sasaki T, Nishimura Y, Tanii H, Hara N, Inoue K, et al. Psychotic-like experiences are associated with suicidal feelings and deliberate self-harm behaviors in adolescents aged 12-15 years. Acta Psychiatr Scand. 2010;121: 301-7.

25. Sugawara N, Yasui-Furukori N, Sasaki G, Sasaki G, Umeda T, Takahashi I, et al. Relationships between suicidal ideation and the dimensions of depressive symptoms among middle-aged population in Japan. J Affect Disord. 2012; 136:819-23.

26. Yong R, Nomura K. Hikikomori is most associated with interpersonal relationships, followed by suicide risks: a secondary analysis of a national cross-sectional study. Front Psychiatry. 2019;10:247.

27. Howarth EJ, O'Connor DB, Panagioti M, Hodkinson A, Wilding S, Johnson J. Are stressful life events prospectively associated with increased suicidal ideation and behaviour? A systematic review and meta-analysis. J Affect Disord. 2020;266:731-42

28. Koyanagi A, Oh H, Carvalho AF, Smith L, Haro JM, Vancampfort D, et al. Bullying victimization and suicide attempt among adolescents aged 12-15 years from 48 countries. J Am Acad Child Adolesc Psychiatry. 2019:58:907-18.

29. van Geel M, Vedder P, Tanilon J. Relationship between peer victimization, cyberbullying, and suicide in children and adolescents: a meta-analysis. JAMA Pediatr. 2014;168:435-42

30. Ministry of Education, Culture, Sports, Science and Technology homepage (2014). Retrieved from http://www.mext.go.jp/component/b_menu/shingi/ toushin/_icsFiles/afieldfile/2014/09/10/1351886_05.pdf. Accessed 13 Mar 2020 
31. Kawabe K, Horiuchi F, Ochi M, Oka Y, Ueno S. Suicidal ideation in adolescents and their caregivers: a cross sectional survey in Japan. BMC Psychiatry. 2016;16:231

32. Hidaka Y, Operario D, Takenaka M, Omori S, Ichikawa S, Shirasaka T. Attempted suicide and associated risk factors among youth in urban Japan. Soc Psychiatry Psychiatr Epidemiol. 2008:43:752-7.

33. Obikane E, Shinozaki T, Takagi D, Kawakami N. Impact of childhood abuse on suicide-related behavior: analysis using marginal structural models. J Affect Disord. 2018;234:224-30.

34. Bannink R, Broeren S, van de Looij-Jansen PM, de Waart FG, Raat H. Cyber and traditional bullying victimization as a risk factor for mental health problems and suicidal ideation in adolescents. PLoS One. 2014;9:e94026.

35. Daine K, Hawton K, Singaravelu V, Stewart A, Simkin S, Montgomery P. The power of the web: a systematic review of studies of the influence of the internet on self-harm and suicide in young people. PLoS One. 2013;8:e77555.

36. Lee SY, Park EC, Han KT, Kim SJ, Chun SY, Park S. The association of level of internet use with suicidal ideation and suicide attempts in south Korean adolescents: a focus on family structure and household economic status. Can J Psychiatr. 2016;61:243-51.

37. Sampasa-Kanyinga $\mathrm{H}$, Roumeliotis $\mathrm{P}, \mathrm{Xu} \mathrm{H}$. Associations between cyberbullying and school bullying victimization and suicidal ideation, plans and attempts among Canadian schoolchildren. PLoS One. 2014:9:e102145.

38. Slonje R, Smith PK. Cyberbullying: another main type of bullying? Scand J Psychol. 2008:49:147-54.

39. Ando S, Kasai K, Matamura M, Hasegawa Y, Hirakawa H, Asukai N. Psychosocial factors associated with suicidal ideation in clinical patients with depression. J Affect Disord. 2013;151:561-5.

40. Berutti M, Dias RS, Pereira VA, Lafer B, Nery FG. Association between history of suicide attempts and family functioning in bipolar disorder. J Affect Disord. 2016;192:28-33.

41. Consoli A, Peyre H, Speranza M, Hassler C, Falissard B, Touchette E, et al. Suicidal behaviors in depressed adolescents: role of perceived relationships in the family. Child Adolesc Psychiatry Ment Health. 2013;7:8.

42. Samm A, Tooding LM, Sisask M, Kõlves K, Aasvee K, Värnik A. Suicidal thoughts and depressive feelings amongst Estonian schoolchildren: effect of family relationship and family structure. Eur Child Adolesc Psychiatry. 2012;19:457-68.

43. Toomey RB, Syvertsen AK, Shramko M. Transgender Adolescent Suicide Behavior. Pediatrics. 2018;142:e20174218.

44. Ikuta N, Koike Y, Aoyagi N, Matsuzaka A, Fuse-Nagase Y, Kogawa K, et al. Prevalence of lesbian, gay, bisexual, and transgender among Japanese university students: a single institution survey. Int J Adolesc Med Health. 2016;29:20150113.

45. Nishida A, Shimodera S, Sasaki T, Richards M, Hatch SL, Yamasaki S, et al. Risk for suicidal problems in poor-help-seeking adolescents with psychoticlike experiences: findings from a cross-sectional survey of 16,131 adolescents. Schizophr Res. 2014;159:257-62.

46. Michelmore L, Hindley P. Help-seeking for suicidal thoughts and self-harm in young people: a systematic review. Suicide Life Threat Behav. 2012;42:507-24.

47. Watanabe N, Nishida A, Shimodera S, Inoue K, Oshima N, Sasaki T, et al. Help-seeking behavior among Japanese school students who self-harm: results from a self-report survey of 18,104 adolescents. Neuropsychiatr Dis Treat. 2012;8:561-9.

48. Ougrin D, Latif S. Specific psychological treatment versus treatment as usual in adolescents with self-harm: systematic review and meta-analysis. Crisis. 2011;32:74-80

49. Yamaguchi S, Ojio Y, Foo JC, Michigami E, Usami S, Fuyama T, et al. A quasicluster randomized controlled trial of a classroom-based mental health literacy educational intervention to promote knowledge and help-seeking/ helping behavior in adolescents. J Adolesc. 2020;82:58-66.

\section{Publisher's Note}

Springer Nature remains neutral with regard to jurisdictional claims in published maps and institutional affiliations.

Ready to submit your research? Choose BMC and benefit from:

- fast, convenient online submission

- thorough peer review by experienced researchers in your field

- rapid publication on acceptance

- support for research data, including large and complex data types

- gold Open Access which fosters wider collaboration and increased citations

- maximum visibility for your research: over $100 \mathrm{M}$ website views per year

At BMC, research is always in progress.

Learn more biomedcentral.com/submissions 